\title{
New morphotypes, cell-wall structures, and elemental distribution of the Gunflint microfossils
}

\author{
K. SASAKI', A. ISHIDA', N. TAKAHATA², Y. SANO ${ }^{2}$, \\ T. KAKEGAWA \\ Department of Earth Science, Graduate School of Science, \\ Tohoku University, Sendai, 9808578, Japan (E-mail: \\ kouhei.sasakiq3@dc.tohoku.ac.jp) \\ 2 Atmosphere and Ocean Research Institute, The University \\ of Tokyo
}

Microfossils in the ca. 1.9 Ga Gunflint Formation (Gunflint microfossils) were studied by previous investigators, although informations of their ultrastructures and chemical compositions, which can constrain their metabolisms, are missing. In this study, in situ analyses were performed on individual microfossils using high spatial resolution Secondary Ion Mass Spectrometry (NanoSIMS), with other standard geochemical analyses to approach the above problem.

New morphological affinities to cyanobacterial akinete, eukaryotes and fungi were found in the present study.

Bilayered cell-wall structures were also discovered in the spherical microfossil. Such multi-layered wall structure are essentially adopted by modern cyanobacteria, to promote complex metabolism and the storage of organelles. Secondary ion mapping for $12 \mathrm{C}-, 12 \mathrm{C} 14 \mathrm{~N}-$, and $32 \mathrm{~S}$ - were obtained on various Gunflint microfossils by NanoSIMS. They showed the similar elemental distribution patterns among several morphotypes. A unique elemental distribution was observed only in globular type microfossils, showing heterogeneous $\mathrm{N}$ and $\mathrm{S}$ distribution between cell wall and inner structure. This indicates that this type of microfossils possibly had a special function, such as production of baeocytes.

Outer parts (i.e., walls) and inner parts of examined microfossils often showed contrast chemistries. Inside organic matter contained iron microcrystals and trace amounts of $\mathrm{Ca}$ or Mo. They imply that successful detection of minerals and elements which are possibly related to cyanobacterial enzyme. Outer parts were generally depleted in $\mathrm{N}$ and enriched in $\mathrm{S}$. In addition, $\mathrm{Na}, \mathrm{K}$, and $\mathrm{Cl}$ were often detected from cell wall, suggesting that the Gunflint microbiota were active in the evaporitic environment.

Our findings not only constrain to microbial activities in the Gunflint ocean, but also provide new keys to understand the evolution of early life and their living environments in the Paleoproterozoic era. 